\title{
The Analysis of Nicknames on Website from the Perspective of Sociolinguistics
}

\author{
Yang Zhao \\ Foreign Languages College, Beihua University, Jilin 132013, China.
}

Key words: screen name, virtual randomness, indispensable.

\begin{abstract}
The nicknames on Website have become an indispensable part of people's daily life. Screen names are generally more casual, and the more unique the better, the more novel the better. However, there are a lot of differences between Chinese and Western screen names, through the comparison of Chinese and Western screen name is helpful to understand the thinking, cultural and psychological thinking and differences between Chinese and Western Internet users in the naming process. In this study, we analyze the characteristics of net names from the perspective of sociolinguistics, and compare the differences between Chinese and Western screen names. Make people understand the meaning and characteristics of the net name. This study will help users to better understand the net name, but also for the Internet users in the acquisition of the net name at the same time to provide some reference, so that they will be better to use the screen in real life.
\end{abstract}

\section{Introduction}

In the network communication, people use net IDs to hide their true identities or to be unconventional. This article applies the theory of social linguistics to analyze constitution and linguistic features of net IDs, and explores the numerous variations and the reasons for them. Based on these, with superficial and deep meanings of net IDs, we focus on language usage of modern netizens. Furthermore, we study the social culture and psychology reflected by net IDs with the explanation of emetics.

Also with the rise and popularity of the Internet, people use the screen to hide the true identity or unconventional, forming a unique cultural landscape. Nickname was originally used as a symbol of the network ID (identification abbreviation, refers to the user name or account) and appeared, with the popularity of the Internet and the development of network language, become more complex.

The setting condition of the screen name is very broad and varied, and can be used in Chinese characters, letters, numbers, special symbols and other complex combinations. Therefore, the name of the user in the network communication, can be true, can also be virtual. On the surface of the screen has a greater randomness, but in fact there are inherent rules. We try to from the composition and language features of net classification, and the variation of rhetoric, net of the social linguistics knowledge inquiry network reflects the social and cultural psychology, which is of great significance for the development of network language.

\section{Linguistic Analysis of Chinese and Western Nickname on Website}

As an organic part of the development of social culture, the network culture is also integrated into the real word. This new culture phenomenon has its social causes and has a great effect on people's lives. It has an irregular structure of Chinese traditional ethics breakthrough in the form that is the inheritance china consciousness free romance in the traditional culture, but also promote china traditional culture consciousness; the organic unity of its intrinsic content both lyrical and artistic, but also reflects the close combination of practical and utilitarian, and reflects the common and vulgar the mix.

Nickname is the deep cultural connotation, its reflect the Chinese users on the local culture and foreign culture of the deep love of the temptation of national consciousness; secondly, it reflects the 
China users lost traditional and modern pursuit of order value consciousness; it reflects perceptual and rational solutions China netizens put exile consciousness of change. Net as a part of social culture, society has distinctive cultural features, to a certain extent reflects the user's personality, occupation and the social group, its changes reflect the impact of Internet on people's lives, at the same time reflect the changes of the times culture.

In the western country, English speaking countries "name light name" and "women with husband's surname", are a reflection of their world outlook, outlook on life and values also reflects their social thoughts, habits and behavior. The system of surnames in English speaking countries is basically the same. English surnames began mainly in Anglo Saxon countries, with the spread of the British Empire in eighteenth Century and spread to the spread of the world. Although there are great differences between Chinese and Western cultures, Chinese and English surnames have a lot in common: Name of occupation. In English, the name of the occupation is similar to the situation of the Chinese language, but the scope of employment is much broader, the name of the occupation name is much more than the name of China. For example, the common Smith surname is a very common name in English speaking countries, because there are various craftsmen in early British society. Such as Goldsmith, Coppersmith, Goldsmith. There are other bakers Baker, barber-Barber, fishermen Fisher, tailor-Tailor, Hunter-Hunter, butcher-Butcher, sailor-Sailor, carpenter-Carpenter are common surnames.

The terrain and physiognomy of residence. For example, Field fields, Hill hills, Brook Creek, Lane alley, Shore coast, Lake-lake, Bush jungle, etc..

Based on the linguistic analysis of Chinese and Western net names, the language forms of Chinese net names can be divided into linguistic signs and non-linguistic signs. Language symbols can be divided into pure Chinese language symbols, non Chinese language symbols, pure Chinese characters, non Chinese language mixed forms.

Pure Chinese language symbol: as for the traditional Chinese, use the pure Chinese language symbol in the nickname on Website also is a usual. Like FA, SHUNQIZIRAN, GUOGUO and ZHIZHE. Non Chinese language sign: for this form of expression, people prefer to use Chinese pinyin, numbers, foreign language, words with foreign language and numbers with foreign language to take their own screen name. Like WEIZIJI, 33497, FOREVER, BOY-BB and ANGEL-1520. Pure Chinese characters and non Chinese characters: People usually use Chinese characters or a combination of numbers and the combination of Chinese and foreign languages, as well as Chinese characters, Chinese Pinyin combination of the name of the form. Like Jiushiaini1314, gudan girl, xinqi seven and woshi xiaomifeng. For non language symbols, people prefer to use pure non linguistic symbols.

In the west, the form of the net name can be divided into the form of letters, non letters, and letters and non letters and mixed. As for form of letters people would like to use Carolinesowter and Lassus. And non letters they also like to use no words with English. Letters and non letters and mixed, westerners prefer to use the combination of letters and foreign languages, such as Gubala Kungfu Online, TranAN'ARKH. It selects two more representative of the net, we can analyze the combination form of network users is likely to do the students abroad, or outside their own country based on foreign culture has a strong interest in hobbies. Gubala Kungfu Online this nickname on Website that means people who like the Kongfu very much. Even though like Kongfu in a crazy state. And TranAN' ARKH the word has a great relationship with Hugo's Notre Dame de Paris.

\section{Sociological Analysis of Chinese and Western Nicknames on Website}

On the surface, Nickname is a code, elegant, vicious, arrogant, low-key, praise and a curse, as long as you can love, netizens can move Xi changed life. But in today's people-oriented society, the vast majority of Internet users in the choice of net name is the main consideration is full of personality, so as to highlight the distinctive features. Many netizens in combination with name, appearance, personality and psychological characteristics, on the net the main endowment virtue can make the organic unity of appearance and the content of the summary, we can through the net behind the 
character of simple speculation, such as: "in the field of wind", immediately let people think of the Internet love nature, love freedom, unfettered life; "gold man" can think of the Internet users are busy for living, but also have a strong ambition, the dream of getting rich; the "wood" is the name of that Internet users introverted, not good words, but sincere honest name often be scanty of words; "jiaoshuhunfanchi" teaching make people think that this is a commitment to the village education friends. That is to say, people choose a netname, they always have some psychological basis, they want to tell others through the net what they want to say, or vent a moment of feeling, or want to let people know that what they love one thing, may also be used can a symbol of their own things, express their aspirations and ideals, show their personality charm, one the other hand, nickname in a certain extent, reflect the character of Internet users themselves, and their occupation social groups are engaged in.

In the sociological characteristics of western nicknames way to analysis, English speaking countries, especially the United States is a melting pot of the world nation, people creative values are very prominent, all have a unique style, so is the pursuit of new in order to be different, their names. For example, a surname Orange, apple Apple, orange Rice rice, wheat Wheat, corn grain and fruits such as Corn, Bacon, Ham, ham and bacon named Cough, Poison, cough poison ashes Ash, it was a bit strange and eccentric. Of course, we are in the translation of English names are the use of transliteration, that is, what to read, what the word translation. For example, Mrs. Bird, Miss Fish Griffith, Mrs. Bird, Mr. Fawkes, miss Mr. Fox, Mr. Strong.

Malinowski, an English anthropologist, referred to the question of meaning in the original language, that language is not only a way of behavior, but also a social function. Human beings are closely related to society, language and society, and human beings are controlled by society, and human beings live in a specific language in which the society lives in the common way of expression. No language is impossible to adapt to society. There are no two identical languages in the world, even if they are similar, they will not have the same social reality.

From the sociological analysis of the Chinese and Western screen names, we see the following features. First of all is the individual character of the national culture. The vocabulary system of a national language can reflect the cultural value orientation of the nation directly and sensitively. In addition, the American linguist Enber: the language of a society can reflect its corresponding culture, one of the names of the performance in the vocabulary or vocabulary. Finally, the German psychologist: the vocabulary of a nation can reveal the nation and the national culture.

\section{Conclusion}

On the basis of collecting and analyzing the net name, we analyze the category and language features of the net name from the perspective of sociolinguistics. Language is not static, it is accompanied by changes in the development of society and the development of change, or even changes in the network name. As a universal language, its influence is growing, from primary school to $\mathrm{PhD}$, English courses cannot figure rarely, this completely different forms of language to let people see the language has such different forms, and people born to change innovation, but also enhance the psychological status of English in Chinese, even will be able to read and speak English as a symbol of identity of higher talents. These are reflected in the net, as many Internet users are in the English name, even only English, even if do not understand English people will also use some letters to Arabia named a pretentious vanity. However, when people use a foreign language, they are mostly treated as a kind of language symbol. Therefore, the English net name has become a popular net name.

\section{References}

[1]. Katrina A Meyer. A Study of Online Discourse at The Chronicle of Higher Education [J]. Innovative Higher Education, 2010 (3). 
[2]. Communication within On-line Forums: The Opportunities, The Constraints and The Value of A Communicative Approach [J]. Michael Hammond. Computers \& Education, 2000 (4). 